\title{
Evaluation of FIT impacts on market clearing price in the restructured power market
}

\begin{abstract}
The development of intermittent wind firms in the restructured power market has required the entry of several creative approaches in evaluating the market clearing price in the restructured power market. This study proposes a model to investigate the seasonal market clearing price by considering the hybrid wind-heat firm. In this article, fixed and variable Feed in Tariff (FIT) is considered and compared as two regulatory policies for wind generation units. Wind resources modeled by using the scenario based technique. Furthermore, strategic behavior of other investors is considered based on the game theory concepts. The Cournot game concept has been applied to determine the Nash equilibrium for each state of stochastic programming. This model has been implemented on a test system. The effects of the fixed and variable FIT and the variations of electricity price cap have been investigated on the profit of each firm in the restructured power market. Moreover, the market clearing price offered for each season and load level.
\end{abstract}

Keyword: Game theory; Market clearing prices; Renewable energy; Restructured power market; Smart grid 